\title{
Approach to Determine Corrosion Propensity in Post-Tensioned Tendons with Deficient Grout
}

\author{
Juan Carlos Rafols ${ }^{1}$, Kingsley Lau ${ }^{2}$, Ivan Lasa ${ }^{3}$, Mario Paredes ${ }^{3}$, Adel ElSafty ${ }^{4}$ \\ ${ }^{1}$ CONCORR Florida, Inc., Merritt Island, USA \\ ${ }^{2}$ Florida International University, Miami, USA \\ ${ }^{3}$ Florida Department of Transportation, Gainesville, USA \\ ${ }^{4}$ University of North Florida, Jacksonville, USA \\ Email: adel.el-safty@unf.edu
}

Received July 11, 2013; revised August 11, 2013; accepted August 18, 2013

Copyright (C) 2013 Juan Carlos Rafols et al. This is an open access article distributed under the Creative Commons Attribution License, which permits unrestricted use, distribution, and reproduction in any medium, provided the original work is properly cited.

\begin{abstract}
After corrosion failure of post-tensioned tendons was identified in a Florida bridge in early 2011, laboratory tests were conducted in this study on extracted sections from the failed tendons to identify the grout properties and makeup leading to the failure and also to elucidate the mechanism of corrosion. The initial steps in identification of PT tendons with a high propensity for corrosion initiation or damaged included a detailed visual inspection and identification of voids in the grout. Voids in tendon can be a result of bleed water formation or construction problems. General characteristics of the deficient grout and corrosion behavior of steel in the affected bridge gave a first approach to assessing grout deficiency and corrosion susceptibility. However, refinements in the understanding of the mechanisms causing grout segregation and the elucidation of the role of sulfates, oxygen content, and pore water $\mathrm{pH}$ in corrosion development are required.
\end{abstract}

Keywords: Post Tensioned; Grout; Dissimilar; Tendon; Corrosion

\section{Introduction}

Corrosion protection of post-tensioned (PT) tendons typically consists of embedding the strand in cementitious grout inside a high density polyethylene (HDPE) duct. The grout provides an ideal high alkalinity environment to promote steel passivation and the duct prevents intrusion of moisture, air, and aggressive chemicals into the tendon. In the past, PT tendon failures have been associated with localized corrosion of strand at void spaces that formed in the tendon due to bleed water accumulation and reabsorption [1,2]. Consequently, grout material specifications established maximum allowable bleed water volume to mitigate corrosion development [3]. However, more recent corrosion failure in PT tendons constructed with grout material conforming to the low-bleed requirements has occurred as well. A corrosion failure of several PT tendons occurred in a bridge in Florida constructed with low-bleed grouts in 2011. In the examination of the failed tendons, voids were sometimes identified but were not consistently associated with severe corrosion development. The deficient grout contained pockets of non-homogeneous material character- ized as a white/chalky or a wet unhardened material. The deficient grout material was typically characterized by having high moisture content, high pore solution $\mathrm{pH}$, low chloride concentration, and high sulfate concentrations. Visual examination and electrochemical testing suggested significant anodic corrosion activity of the strand, predominantly in the presence of the deficient grout [4].

Inspection of the tendons for grout material deficiencies and corrosion development has been a challenge without the wide availability and acceptance of appropriate non-destructive testing techniques. Areas of anticipated corrosion susceptibility such as at tendon high points and grout void locations were of particular interest but locations with grout deficiencies may be present elsewhere in the tendon as well. Although subjective to interpretation, conventional hammer impact sounding test has been used to help identify the presence of voids along the free length of external tendons [5], but its use to identify segregated grout was limited. Visual inspection to identify damage in the ducts and controlled removal of portions of the HDPE duct to expose the grout provided indication of the grout condition and the manifestation of severe corrosion but cannot provide informa- 
tion on corrosion rates and other important chemical and environmental conditions such as exposure to atmospheric oxygen, differential moisture content, and accumulation of aggressive chemical species may aggravate the corrosion development and enhance macrocell corrosion formation. Further uncertainty arises after repair of tendons with deficient grout. Non-pervasive corrosion developed on strands at the void-grout interface may be mitigated after repair if the pre-existing grout and repair grout do not have material deficiencies [6]. Nonetheless, cases like the Varina Enon Bridge in Virginia, have reported corrosion failures at grout void locations in relatively short periods of time after being repaired [7]. In this paper, a description of important material parameters, test methods, and initial results from a case study are presented to help characterize the conditions in the PT tendons with deficient grout materials and help identify the propensity for possible corrosion development.

\section{Grout Material}

The moisture content in grout is typically associated with the water in the cement hydrate as well as in the capillary pore spaces of the cement and filler. The moisture content can vary depending on the grout mix design and exposure conditions but excessive moisture presence within the grout has been associated with grout material deficiency and corrosion development.

In the deficient grout, when segregation occurs, moisture may create in part saturated pore spaces in a nonhomogenous material with separation of cement and filler materials. The role of the moisture within the segregated grout may have significant impact on the rheology of the highly engineered grout materials [8], but its effects on corrosion initiation as well as the effect of pore water chemistry differences has not been elucidated. Presence of excessive moisture in the grout would lead to more permeable material with degraded electrical properties conducive to corrosion propagation. Comparative moisture content in grout samples can be determined gravimetrically by drying the material. Also, the use of electrical techniques including Electrochemical Impedance Spectroscopy (EIS) provides means to characterize the moisture content of a grout without having to alter the original state of the material [9]. Work by Lau, Rafols, and Paredes [10], has suggested that this technique can also be used to characterize dissimilar grouts in repaired tendons. The grout solution resistance, determined by EIS, is in part characteristic to grout permeability and can vary by mix design, extent of grout hydration, and exposure conditions; however, it is also sensitive to moisture content in the grout. The lower solution resistance may be indicative of material where better ionic coupling of active corrosion sites and the extended regions on the steel strand may develop and support mac- rocell formation.

The chemistry of grout and other cementitious material promote steel passivity by providing alkaline $\mathrm{pH}$ conditions above 11.5 [11]. The passive layer is less stable at $\mathrm{pH}$ levels below 11.5 and $\mathrm{pH}$ decrease can be attributed to the reaction of atmospheric carbon dioxide with pore water. Grout pore water $\mathrm{pH}$ can be measured from pore solution samples obtained from the grout obtained following pore water expression procedures by Barneyback and Diamond [12] or ex situ leaching methods as proposed by Li, Nam and Hartt [13]. The presence of chloride ions can also cause localized failures in the passive layer. Sources of chloride ion in PT tendons concentrations that can lead to corrosion initiation can include runoff drainage water that enters the tendon through defects in the duct [14], enhanced chloride content that may exist from raw materials $[15,16]$, and localized ion chloride enrichment due to evaporation of bleed water [17]. The role of sulfate content in corrosion initiation has not been well defined, but it has been suggested that it may play a role in the destabilization of the passive layer protection of the steel $[7,18,19]$. Identification of the amount of oxygen available for reaction within the duct is important to elucidate the corrosion mechanism of the observed corrosion failures of PT tendons with deficient grout. Exposure to atmospheric air would promote corrosion activity. As such, during the physical evaluation of the tendons, improperly sealed outlets, inlets, joints or cracked ducts should be clearly identified and corrective actions taken to mitigate these. Corrosion of PT tendons with segregated grout was suggested to be initiated in high $\mathrm{pH}$ environments with the presence of large cathodic polarization that may be present in oxygen deficient environments in crevices, such as in the inter-strand and strand interstitial spaces [20].

\section{Electrochemical Testing and Lab Investigation}

In order to independently monitor the behavior of the repair materials, a test setup was fabricated to simulate strands embedded in a no repair and no void environment using new (clean surface) and pre-rusted wires. Wires were extracted from strand sections and a cable wire was attached to one end, and both ends were later coverd in an epoxy resin to protect the connection and the end of the king wire. To develop rust, one of the king wire assemblies was stored in a $100 \%$ relative humidity environment for approximately 30 days. The strand assembly was inserted into a caped pvc pipe 2 in. diameter and 12 $1 / 2$ in. length. In these samples a titanium reference electrode and an auxiliary referenced electrode were introduced. The reference electrode was a 2 in. length and 1/8 in. diameter activated titanium rod, the auxiliary electrode was a 1 in. by 2 in. activated titanium mesh in- 
stalled on the inner sides of the pvc pipe, opposed to each other. Samples were filled with the base grout $(0.45$ water-cement ratio paste) and pre-bagged grouts. After casting, a layer of approximately $1 / 2$ in. of epoxy resin was casted on top of the sample to completely encapsulate the tendon. On the side of the sample, $1 / 2$ in. diameter openings were made using a drill bit to provide access to the grout to take OCP measurements. These openings were kept sealed at all times except when taking measurements. Open Circuit Potential, Solution Resistance, Linear Polarization Resistance, Electrochemical Impedance Spectroscopy and Potentiodynamic Scan were performed in these samples. Also, laboratory samples were fabricated to simulate repaired voids with dissimilar grouts and to simulate deficient repairs of voids and/or aggressive environment to exposed strand in a void. To better describe and characterize the significance of the presence of sulfates in high $\mathrm{pH}$ solution, additional laboratory, samples with simulated pore water solution were built. Open Circuit Potential, and Macrocell Current testing were performed in this investigation.

Measurement of local corrosion potential of the strand with respect to a standard reference electrode may give indication of corrosion activity but testing requires contact with the steel strand and placement of a reference electrode by exposing the embedded grout. Linear Polarization Resistance (LPR) is a method of determining instantaneous corrosion rate of the steel. Restrictions of electrode placement on the tendon limit the practical use of this method [21,22]. From LPR test results, the polarization resistance, $\mathrm{Rp}$, of the steel is calculated from the Equation (1) and the corrosion current, $\mathrm{I}_{\text {corr }}$, can be calculated by Equation (2),

$$
\begin{aligned}
& \mathrm{Rp}=\Delta \mathrm{E} / \Delta \mathrm{I} \\
& \mathrm{I}_{\text {corr }}=\mathrm{B} / \mathrm{Rp}
\end{aligned}
$$

where $\Delta \mathrm{E}$ is the change in voltage, $\Delta \mathrm{I}$ is the change in current, B is the Stern-Geary constant (assumed to be 26 $\mathrm{mV}$ for active steel and $50 \mathrm{mV}$ for passive steel). If the surface area (Anodic steel area), A, being polarized is accurately known, the current density $i_{\text {corr }}$ can be calculated by Equation (3).

$$
\mathrm{i}_{\text {corr }}=\mathrm{I}_{\text {corr }} / \mathrm{A}
$$

Electrochemical Impedance Spectroscopy (EIS) is a technique that can also be used to determine corrosion rates of steel as well as provide information on the grout bulk properties. Similar electrode placement restrictions as for LPR limit the practical use of this method too. In this technique, an alternating potential is applied at varying frequencies and the resulting alternating current is measured. Macrocell current development give indication of net corrosion activity of discrete embedded metal members by coupling the actively corroding metal to the net cathodic regions created by the corrosion cell [23].
The current can be measured by connecting a zero-impedance ammeter between the anodic and cathodic electrodes and measuring the current directly or measuring voltage drop across a shunt resistor [11]. Grouts that have high electrical resistivity may have reduced macrocell development despite having active corrosion conditions.

\section{Case Study}

In this section, results from the preliminary analysis of samples obtained from failed tendons in a Florida Bridge earlier described are presented. The deficient grout was observed in localized portions of the tendon free length and appeared as a white/chalky material or in a wetplastic unhardened state. In some instances, longitudinal voids were identified in the tendon. The moisture content was clearly differentiated between normal and deficient grout. Grout with normal consistency showed low values of moisture content in the range of $10 \%$ to $20 \%$ by mass. The deficient grout characterized as white/chalky material had moisture content greater than $40 \%$ and deficient grout characterized as wet-plastic material had moisture content up to $70 \%$. As shown in Figure 1, the various modalities of deficient grout described for the free length portion of the tendon was stratified within some anchor caps where the wet-plastic material was at the upper portion of the cross-section, hardened grout was at the bottom portion of the cross-section, and grout with intermediate descriptions in between. Severe corrosion was evident in the upper portion of the anchor cross-section but the extent of corrosion of the strand within the anchorage was not determined at the time of this writing. Moisture content and a partial listing of pore water constituents of the grout from one of the anchor caps measured by ion chromatography and inductively coupled plasma-atomic emission spectrometry from those layers as well as a control mix are shown in Figure 1.

Acid soluble chloride content was found to be within specifications limits; however, results from ion chromatography of the extracted grout pore solution showed sulfate concentrations as high as $8000 \mathrm{ppm}$ but were as high as 10,000-ppm [4] in samples of the deficient material at other tendon locations. Measurement of grout $\mathrm{pH}$ yielded values typically greater than 12 regardless of grout consistency with the exceptions of grout samples collected in the vicinity of strand with severe corrosion. Although relatively high alkalinity was maintained in the segregated grout, the corrosion mechanism proposed elsewhere [20], where active corrosion was maintained due to high $\mathrm{pH}$ and large cathodic polarization in part due to low oxygen availability in crevice regions, may not have been the primary cause here. In the case study, it was apparent that sedimentation and accumulation of silica fume in the segregated grout may have slightly 

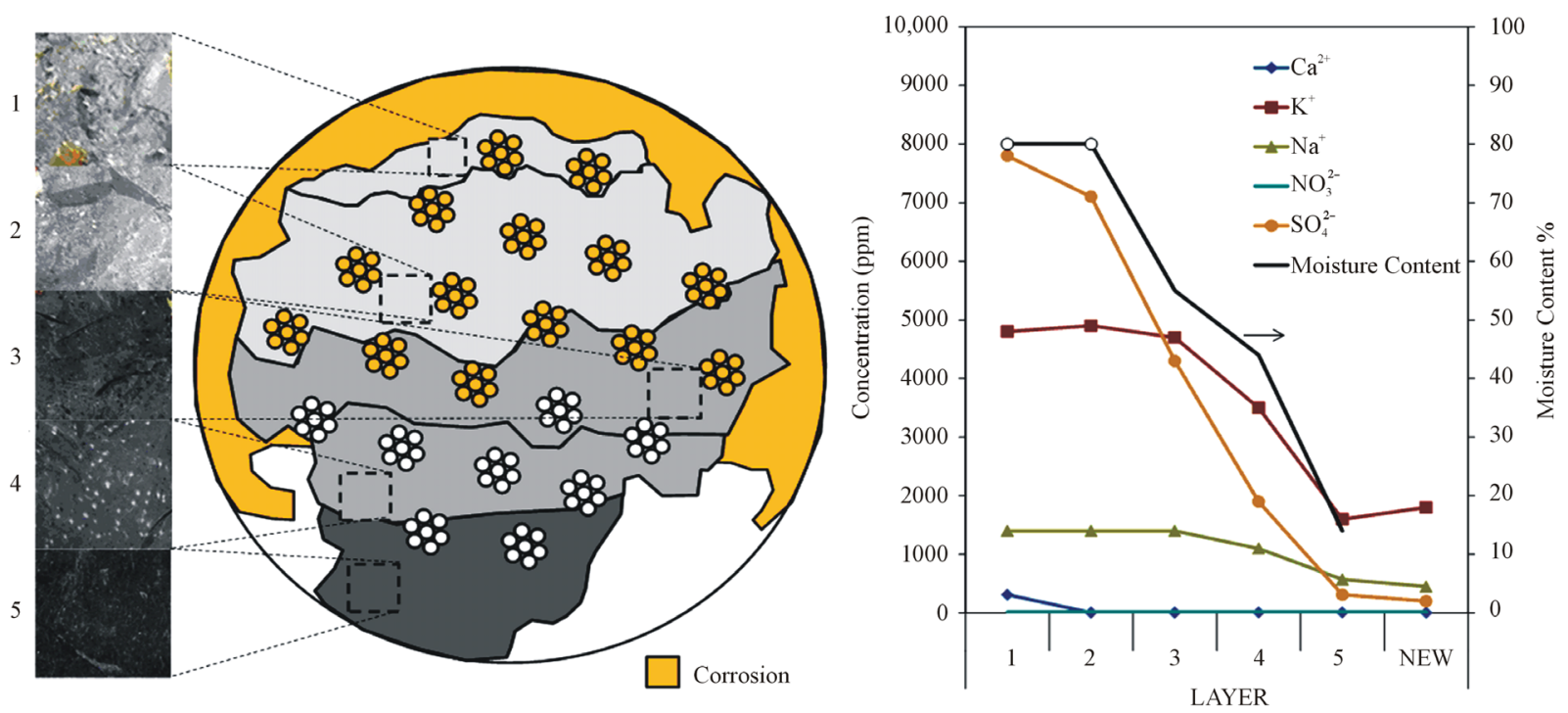

Figure 1. Grout material characteristics in tendon anchor cap.

reduced the $\mathrm{pH}$. Additionally, corresponding to the high sulfate presence, ettringite crystals (that may not be stable in very high $\mathrm{pH}$ ) were prominent in segregated grout.

Consistent with the higher moisture content in the deficient grout, lower solution resistance (indicative of a permeable material conducive for corrosion development) was measured by EIS for field extracted tendon segments, Figure 2.

The effect of galvanic interaction between strand in localized tendon locations with deficient grout and coupled with strand in hardened grout was tested. The open circuit potential (OCP) of strand embedded in deficient grout was more negative than OCP of strand embedded in hardened grout. As expected, coupling of sections resulted in a mixed potential intermediate to the OCP of the strand prior to coupling, Figure 3(a). The corrosion current, $\mathrm{I}_{\text {corr, }}$ measured by linear polarization resistance

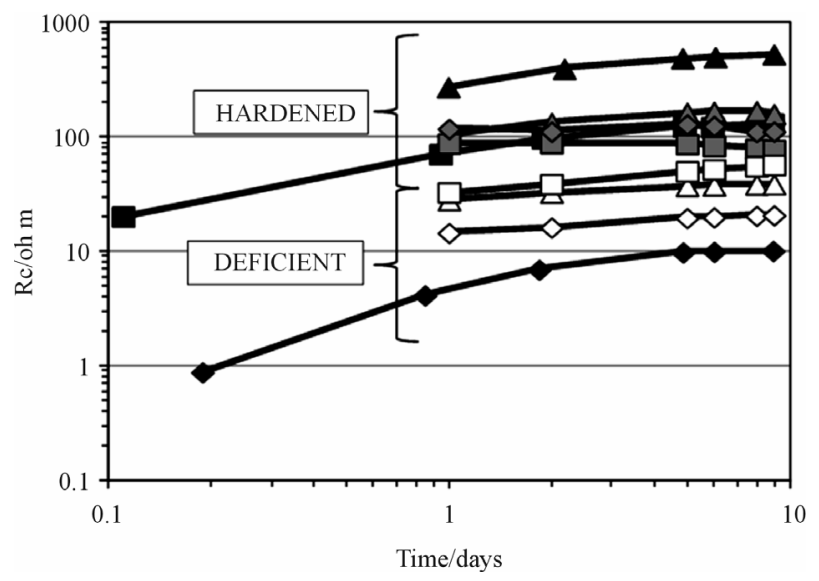

Figure 2. Developed solution resistance of existing hardened and deficient grouts. Time shown from test sample fabrication. measurements was greater in sections containing the deficient material and that coupling of the individual sections resulted in an increase of the overall corrosion current, as seen in Figure 3(b). Enhanced corrosion rates are expected when the ratio of cathode to anode area increases. In the laboratory testing described in detail elsewhere [6], the area ratio of steel embedded in deficient grout to steel embedded in hardened grout was approximately $1: 1$. Macrocell currents were as high as 100 $\mu \mathrm{A}$ in the test samples and were $\sim 40 \mu \mathrm{A}$ after 3 months of testing [6].

The greatest challenge in assessing grout material deficiencies and corrosion development in PT tendons was accessibility (especially in regions such as anchorages and deviators). Here testing was conducted on extracted samples in the laboratory after demolition of failed tendons. With large sections of extracted tendons, $\sim 3-5 \mathrm{ft}$. long, the embedded grout was able to be stored without significant material aging until sampling and testing was ready. In the field, detailed testing of grout material from within the anchorages could not be made and general assessment was made by drilling and visual examination. Even for tendon free lengths, controlled in-situ examination of the tendons was mostly relegated to visual surveys. When material sampling was possible, the quantity of extracted material was limited and often was highly disturbed during the extraction process. Some grout samples may have dried out and the extracted samples may only have been retrieved in loose powder form. Depending on the condition of the extracted grout samples, complete characterization of the material as described Section 2 was not possible. Generally, chloride analysis and powder x-ray diffraction (XRD) was conducted with prepared samples in powder form but bulk grout analysis including petrographic analysis, moisture content, and 


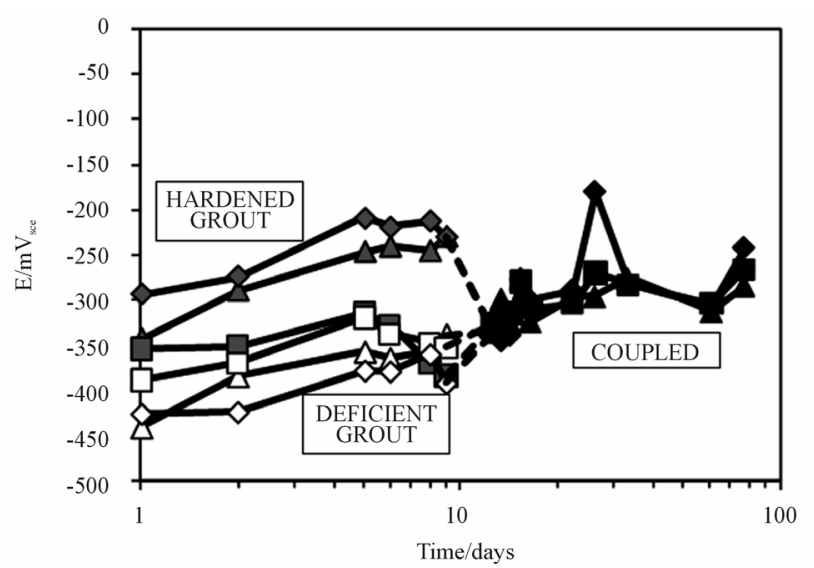

(a)

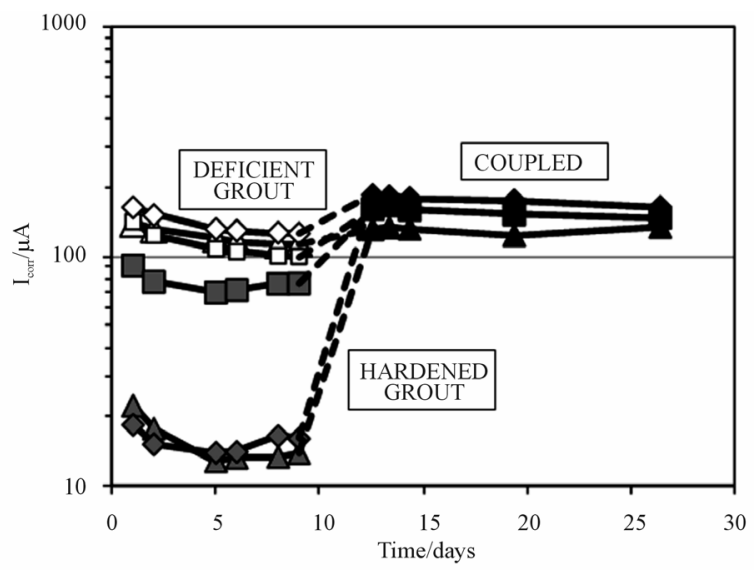

(b)

Figure 3. Corrosion potential and current of strand coupled in hardened and deficient grout. (a) Open circuit potential before and after sample coupling; (b) Corrosion current before and after coupling.

testing involving electrical methods such as grout resistivity required larger sample geometries. The identification of ettringite crystals in deficient grouts (representative of enhanced sulfate concentrations) by powder XRD was sensitive to grout drying conditions $[4,24,25]$. Also, the deficient grout with high moisture content quickly dried upon exposure and showed indications of shrinkage cracking. Pore water extraction yielded less solution upon sample drying, and carbonation of the grout pore water could become significant with grout in powder form.

The limitations of electrochemical testing (such as corrosion potential mapping, LPR and EIS) detailed elsewhere $[26,27]$ also applied here but further complications even in laboratory settings arose due to the necessity to incorporate reference and auxiliary electrodes without disturbing the original grout material or introducing dissimilar grout materials. EIS has sensitivity to the grout condition but the impedance response could be complicated and require consideration of testing artifacts including non-uniform current distribution $[28,29]$. In conjunction to resolving the cause of the formation of deficient grout, additional testing of the deficient grout material will need to be completed to elucidate the role of chemical and environmental characteristics in the development of corrosion and subsequent failure of the tendons. Among issues to be resolved include defining the cause of corrosion initiation in pore solution containing high sulfate concentrations and identifying the contributing role of pore water $\mathrm{pH}$ and oxygen content.

\section{Conclusion}

Important grout properties and characteristics need to be clarified to elucidate the cause of corrosion failure of steel strand in deficient grout materials that have otherwise high $\mathrm{pH}$ and low chloride concentrations. The dif- ficulties in grout sampling and testing encountered during preliminary testing of deficient grout presented more challenges to be addressed. General characteristics of deficient grout associated with corrosion failure of tendons and evidence of macrocell formation and enhanced corrosion give a first approach to assessing grout deficiency and corrosion susceptibility but refinement in the understanding of the mechanisms causing grout segregation and the elucidation of the role of sulfates, oxygen content, and pore water $\mathrm{pH}$ in corrosion development is required.

\section{REFERENCES}

[1] A. Sagues, R. Powers and H. Wang, "Mechanism of Corrosion of Steel in Post Tensioned Grouted Assemblies," NACE Corrosion, Houston, 2003.

[2] W. Hartt and S. Venugopalan, "Corrosion Evaluation of Post-Tensioned Tendons on the Mid Bay Bridge in Destin, FL.," Florida Department of Transportation Research Center, Tallahassee, 2002.

[3] Corven Engineering Inc., "New Directions for Florida Post-Tensioned Bridges," Florida Department of Transportation, Tallahassee, 2002.

[4] K. Lau, I. Lasa, M. Paredes and J. C. Rafols, "Laboratory Corrosion Assessment of Post-Tensioned Tendons Repaired with Dissimilar Grout," NACE Corrosion, Houston, 2013.

[5] D. Trejo, S. B. Im, R. G. Pillai, M. B. D. Hueste, P. Gardoni, S. Hurlebaus and M. Gamble, "Effect of Voids in Grouted Post-Tesioned Concrete Bridge Construction: Inspection and Repair Manual for External Tendons in Segmental, Post-Tensioned Bridges," Texas Transportation Institute, Austin, 2009.

[6] J. C. Rafols, "Corrosion of Post-Tensioned Tendons Repaired with Dissimilar Grout," Unplublished Master's Thesis, University of North Florida, Jacksonville, 2012.

[7] M. M. Sprinkel, "Varina Enon Tendon Failure," Virginia Transportation Research Council, Charlottesville, 2009. 
[8] M. Eriksson, M. Friederich and C. Vorschulze, "Variations in the Rheology and Penetrability of Cement-Based Grouts-An Experimental Study," Cement and Concrete Research, Vol. 34, No. 7, 2004, pp. 1111-1119. doi:10.1016/j.cemconres.2003.11.023

[9] K. Lau and A. Sagues, "Coating Conditions Evaluation of Epoxy Coated Rebars," ECS Transactions, Vol. 3, No. 13, 2007, pp. 81-92. doi:10.1149/1.2721432

[10] K. Lau, M. Paredes and J. C. Rafols, "Corrosion Evaluation of Post-Tensioned Tendons with Dissimillar Grout," NACE Corrosion, Salt Lake City, 2012.

[11] A. Bentur, S. Diamond and N. Berke, "Steel Corrosion in Concrete, Fundametals and Civil Engineering Practice," E \& FN Spon, London, 1997.

[12] R. Barneyback and S. Diamond, "Expression and Analysis of Pore Fluids from Hardened Cement Pastes and Mortars," Cement and Concrete Research, Vol. 11, No. 2, 1981, pp. 279-285. doi:10.1016/0008-8846(81)90069-7

[13] L. Li, J. Nam and W. H. Hartt, "Ex Situ Leaching Measurement of Concrete Alkalinity," Cement and Concrete Research, 2004, pp. 1-7.

[14] Corven Engineering, Inc., "Mid-Bay Bridge Post-Tensioning Evaluation," Florida Department of Transportation, Tallahassee, 2001.

[15] S. K. Lee, "Bridge Deterioration: Part 2-Bridge Deterioration Caused by Corrosion," Materials Performance Journal, Vol. 51, No. 2, 2012, pp. 2-7.

[16] S. K. Lee, "Literature Review of Chloride Threshold Values of Grouted Post-Tensioned Tendons," Federal Highway Administration, FHWA-HRT-12-067, McLean, 2012.

[17] H. Wang and A. Sagues, "Corrosion of Post-Tensioning Strand," Florida Department of Transportation, Tallahassee, 2005.

[18] O. Al-Amoudi and M. Maslehuddin, "The Effect of Chloride and Sulfate Ions on Reinforcement Corrosion," Cement and Concrete Research, Vol. 23, No. 1, 1993, pp. 139-146. doi:10.1016/0008-8846(93)90144-X
[19] V. K. Gouda and W. Y. Halaka, "Corrosion and Corrosion Inhibition of Reinforcing Steel: II. Embeded in Concrete," British Corrosion Journal, Vol. 5, No. 5, 1970, pp. 204-208. doi:10.1179/000705970798324478

[20] L. Bertolini and M. Carsana, "High pH Corrosion of Prestressing Steel in Segregated Grout," Dipartimento di Chimica, Materiali e Ingegneria Chimica "G. Natta", Politecnico di Milano, Milano, 2011.

[21] H. W. Song and V. Saraswathy, "Corrosion Monitoring of Reinforced Concrete Structures-A Review," International Journal of Electrochemical Science, Vol. 2, No. 1, 2007, pp. 1-28.

[22] D. A. Jones, "Principles and Prevension of Corrosion," 2nd Edition, Prentice Hall, New Jersey, 1996.

[23] M. Hansson, A. Poursaee and S. Jaffer, "Corrosion of Reinforcing Bars in Concrete," Portland Cement Association, Skokie, 2007.

[24] N. J. Crammond, "Quantitative X-Ray Diffraction of Ettringite, Thaumasite and Gypsum in Concretes and Mortars," Cement and Concrete Research, Vol. 15, No. 3, 1985, pp. 431-441. doi:10.1016/0008-8846(85)90116-4

[25] Portland Cement Association, "The Effect of Secondary Ettringite Formation on the Durability of Concrete: A Literature Analysis," Portland Cement Association, 1992.

[26] A. Sagues, "Corrosion Measurement Techniques for Steel in Concrete," NACE Corrosion, Houston, 1993.

[27] J. A. González, J. M. Miranda, N. Birbilis and S. Feliu, "Electrochemical Techniques for Studying Corrosion of Reinforcing Steel: Limitations and Advantages," Corrosion Journal, Vol. 61, No. 1, 2005, pp. 37-50.

[28] E. Barsoukov and J. Macdonald, "Impedance Spectroscopy Theory, Experiment, and Applications," Wiley-Interscience, New Jersey, 2005.

[29] B. Hope and A. Ip, "Corrosion and Electrical Impedance in Concrete," Cement and Concrete Research, Vol. 15, No. 3, 1985, pp. 525-534. doi:10.1016/0008-8846(85)90127-9 